\title{
Optimum size, position and number of cables in cable-stayed bridges
}

\author{
C. Cid, A. Baldomir, S. Hernández \& M. Cid Montoya \\ Structural Mechanics Group, School of Civil Engineering, \\ University of A Coruña, Spain
}

\begin{abstract}
A methodology to obtain the minimum weight of cables in cable-stayed bridges has been developed. The number of cables, anchor positions on the deck, the crosssectional areas and post-tensioning cable forces have been considered as design variables simultaneously in the optimization process. Two different strategies are proposed using both genetic and gradient-based optimization algorithms. Finally, the Rande Bridge (Vigo, Spain) has been chosen as the application example of both approaches.
\end{abstract}

Keywords: cable-stayed bridges, optimization, cable existence, cable anchor position, prestressing forces, gradient-based algorithm, genetic algorithms.

\section{Introduction}

Cable-stayed bridges have experimented a significant development becoming one of the most popular typology for long span bridges. The span length has increased dramatically leading to a high importance of the cable system with respect to the whole structure. Relevant examples are the Stonecutters Bridge or the Sutong Bridge, with central span of $1018 \mathrm{~m}$ and $1088 \mathrm{~m}$, respectively and the world record, the Russky Bridge with a main span of $1104 \mathrm{~m}$ length.

Many researchers have studied the evaluation of the optimum post-tensioning cable forces under self-weight [1-3] as well as the optimum cable section given the anchor position of cables on the deck [4]. The height, width and plate thickness of simplified deck and pylon were also considered as design variables and the cable anchor positions on the deck [5-7]. In these studies, a maximum number of seven stays were considered as well as the same number of cables each side of the towers. Recent studies have taken into account the construction stages in concrete 
decks into the optimization problem as presented by Martins et al. [8]. A new approach proposed by Baldomir et al. [9] considers a multi-model optimization technique to minimize the cable weight in a multi-span cable stayed bridge with crossing cables.

The previous approaches consider the number of cables as a fixed design parameter. So no chances were given to the idea of increasing the number of cables if it could provide a lower weight in the cable system. Hence an approach to get more competitive designs, being able to define the best number of cables and their anchorage position along the deck, apart from the cross-sectional areas and posttensioning cable forces has been proposed. Two optimization strategies are described using both genetic and gradient-based algorithms. A MATLAB code [10] has been programmed together with use of the commercial finite element software ABAQUS [11] in order to evaluate the minimum weight of stays.

\section{Definition of the structural model}

A single-span cable-stayed bridge has been considered in this research. The generic dimensions are shown in Figure 1.

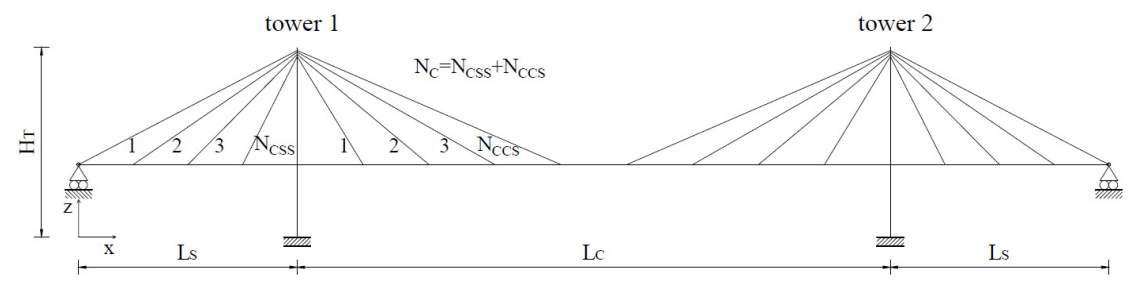

Figure 1: Generic structural model.

The 2D finite element model is composed by beam elements (B21) for the deck and towers and for truss elements (T2D2) for the cables. The towers are built up in the foundations. The connection between the deck and the towers was modelled as a kinematic coupling, linking their vertical displacements, but allowing the longitudinal displacement and rotations of the deck. Cables-deck and cables-tower connections were designed as "tie" constraints [7]. Doing so, it is guaranteed that the relative displacements between both entities are equal, allowing the rotational degree of freedom. These constraint entities make independent the cable-deck union from the mesh procedure, since it is no necessary create compatible meshes between deck and cables, making easier the implementation procedure when the position of the cables on the deck is considered as design variable.

\section{Optimization strategies}

\subsection{General definition of the optimization problem}

The aim is to define a strategy to reduce the steel volume in the cable system. The objective function expressed in (1) is always referred to the half of the total volume of the cables due to the symmetry of the structure. 


$$
\min F=\sum_{i=1}^{N_{C}} L_{i} \cdot x_{i}
$$

being $x_{i}$ and $L_{i}$ the cross sectional area and the length of the $i$-esime cable. The design variables are the number of cables in the bridge, the anchorage position on the deck, the cross sectional areas and the prestressing forces, modelled as thermal loads through the equation:

$$
\sigma_{\text {cable }, \mathrm{i}}=\alpha \cdot \Delta T_{\text {cable }, i} \cdot E_{\text {cable }} \quad \text { with } \quad \alpha=1 \cdot 10^{-5}{ }^{\mathrm{o}} \mathrm{C}^{-1}
$$

Anchor locations of cables in side span $\left(N_{C S S}\right)$ can be at any coordinate value of its length as well as cables in the left-half of the central span $\left(N_{C C S}\right)$, which can oscillate between the tower $\mathrm{x}$-coordinate and the mid span. It must be noticed that the value of the cross sectional areas represents the two planes of the cable system for the real bridge. From now on, when referring to the number of cables in the mid length of the bridge $\left(N_{C}\right)$ will be the sum of cables in the side span $\left(N_{C S S}\right)$ and the cables in the half of the central span $\left(N_{C C S}\right)$, that represent half of the total number of cables of the bridge as can be seen in Figure 1.

Therefore, the number of design variables is the half of the number of cables due to the symmetry of the structure. The design constraints included in the problem are the axial stress of the cables, displacement of deck and towers, as well as normal stress in the deck section. Furthermore, it must be guaranteed that the minimum distance between two cables is at least 2 meters.

\subsection{Optimization strategy 1: Genetic Algorithms (GA)}

The natural approach for considering the number of cables as a design variable is associating the existence of the cable to a binary variable. Mixed Integer Nonlinear Programming (MINLP) allows the use of discrete and continuous variables at the same time. In this case the existence of each cable is associated to a discrete variable taking the values 0 (cable does not exist) and 1 (cable exists). Among many others, the GA of MATLAB was chosen to carry out the optimization process. The full set of design variables considered are included in a vector with the following structure:

$$
\mathbf{x}=[\underbrace{x_{1}, \ldots, x_{N_{C}}}_{\text {cable existence }}, \underbrace{x_{N_{C}+1}, \ldots, x_{2 N_{C}}}_{\begin{array}{c}
\text { cable anchorage position } \\
\text { in the deck }
\end{array}}, \underbrace{x_{2 N_{C}+1}, \ldots, x_{3 N_{C}}}_{\text {cross sectional areas }(A)}, \underbrace{x_{3 N_{C}+1}, \ldots, x_{4 N_{C}}}_{\text {prestressing forces }}]
$$

being $x_{1}, \ldots, x_{N c}$ the set of discrete variables, which can adopt the values 0 or 1 and $x_{N c+1}, \ldots, x_{4 N C}$ the set of continuous variables.

\subsection{Optimization strategy 2: Gradient-based optimization method}

This approach consists of using a gradient-based optimization algorithm having the limitation of using continuous variables exclusively. In order to simulate the effect of considering the number of cables as design variables, it has been set a lower bound for the cable areas of $10^{-6} \mathrm{~m}^{2}$. If a large enough number of cables is included into the bridge model some of them will tend to its minimum area, since the volume of cable system is the objective function to minimize. After eliminating 
them, the next stage consists on a second optimization, considering as design variables only the area and prestressing forces, with the anchorage positions obtained from the previous stage. This optimization is necessary because after suppressing some cables, some updating need to be done to satisfy the design constraints properly. In a third stage, the cross-sectional areas of the cables are approximated to the nearest integer number of commercial strands. The vector of design variables is expressed as follows:

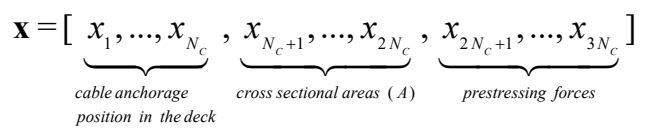

\section{Application example}

\subsection{Bridge description}

In this research the Rande bridge, located in Vigo (Spain), was selected as example for generating the structural model. The geometric description of the bridge appears in Figure 2. The longest cables are separated $2 \mathrm{~m}$ from the top of the tower, and the next cables are spaced $0.5 \mathrm{~m}$ between them. The cross-section of the deck is shown in Figure 3. The mechanical properties are: area of $0.7603 \mathrm{~m}^{3}$, lateral bending inertia of $0.4219 \mathrm{~m}^{4}$ and vertical bending inertia of $42.3472 \mathrm{~m}^{4}$. The solid lines indicate the main section of the deck and the dashed lines represent the transversal stiffeners uniformly distributed along the deck each $3.5 \mathrm{~m}$.

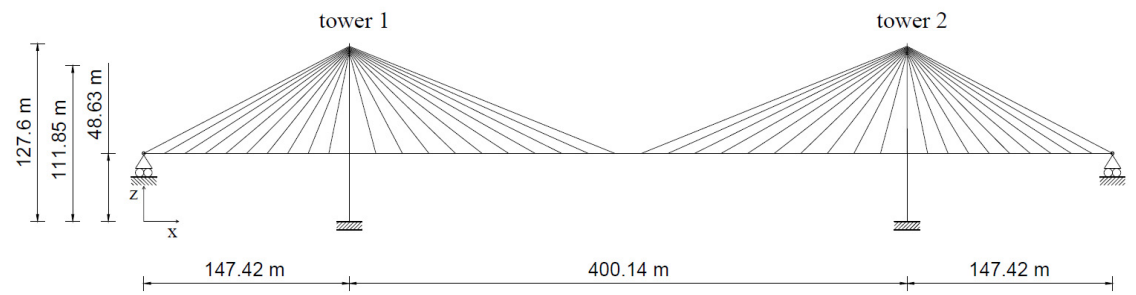

Figure 2: $\quad$ 2D structural simplified model of Rande bridge.

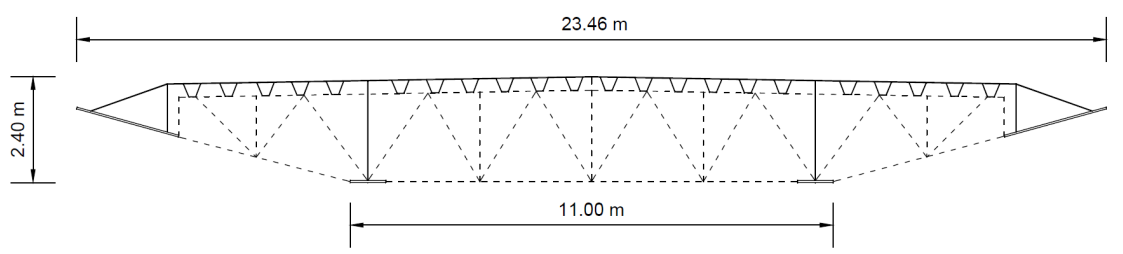

Figure 3: Real cross section of Rande bridge.

The materials are steel for the cables and deck and concrete for the towers. A longitudinal deck load of $138.92 \mathrm{kN} / \mathrm{m}$ was applied to represent the dead loads and the weight of steel structural elements. An ultimate tensile strength for the cables, 
$f_{p k}=1860 \mathrm{MPa}$ and a Young's modulus of $186 \mathrm{GPa}$ were considered. These data were extracted from the original project. A live load of $5 \mathrm{kN} / \mathrm{m}^{2}$ corresponding to a live load is $q=90 \mathrm{kN} / \mathrm{m}$ was applied. The load cases considered are shown in Figure 4.

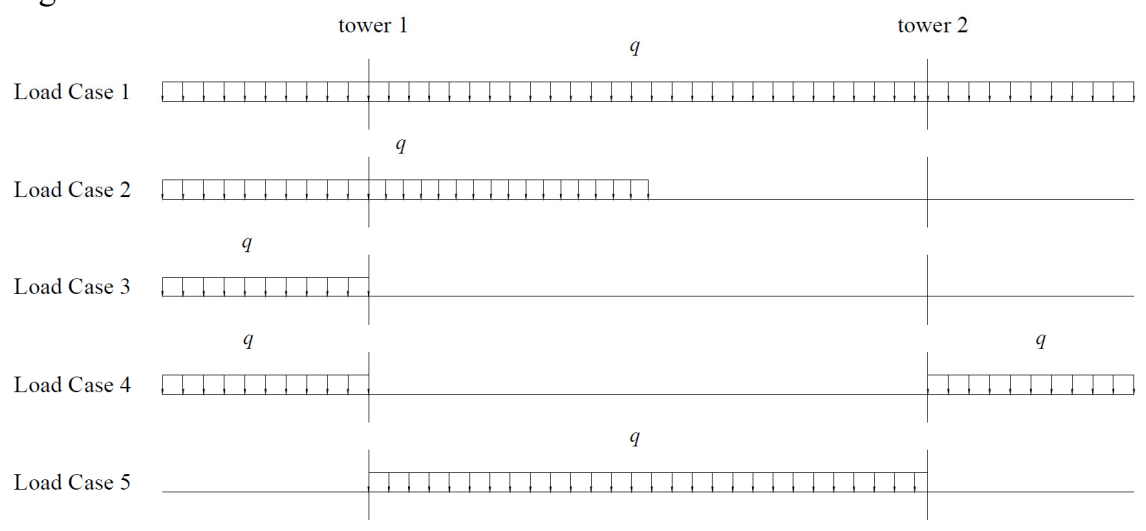

Figure 4: Load cases considered for the analysis.

\subsection{Numerical results}

\subsubsection{Strategy 1: genetic algorithms}

The optimization problem is formulated as follows:

$$
\min F=\sum_{i=1}^{N_{c}} x_{i} \cdot x_{2 N_{c}+i} \cdot L_{i}
$$

subject to

$$
\begin{aligned}
& 0<\sigma^{k}\left(x_{i}\right) \leq \sigma_{M} \quad i=1, \ldots, N_{C} \quad k=0, \ldots, L C \\
& \left|w_{j}^{\text {self-weight }}\right| \leq w_{\max }^{\text {self }- \text { weight }} \quad j=1, \ldots, N_{D} \\
& \left|w_{j}^{k}\right| \leq w_{\max }^{k} \quad j=1, \ldots, N_{D} \quad k=1, \ldots, L C \\
& \left|u_{\text {tower }, p}^{\text {self-wht }}\right| \leq u_{\max }^{\text {self-weight }} \quad p=1,2 \\
& \left|u_{\text {tower }, p}^{k}\right| \leq u_{\max }^{k} \quad p=1,2 \quad k=1, \ldots, L C \\
& \left.\begin{array}{l}
\sigma_{C} \leq \sigma_{\text {top }, j}^{k} \leq \sigma_{T} \\
\sigma_{C} \leq \sigma_{\text {bottom }, j}^{k} \leq \sigma_{T}
\end{array}\right\} \quad j=1, \ldots, E_{D} \quad k=0, \ldots, L C \\
& \left|x_{i+1}-x_{i}\right| \geq 2 \quad i=N_{C}+1, \ldots, 2 N_{C}
\end{aligned}
$$

where $\sigma^{k}\left(x_{i}\right)$ is the tensile stress in the cable $i$ for the load case $k, \sigma_{M}$ the maximum allowable tensile stress in cables, $w_{j}^{k}$ the vertical displacement of 
the node $j, w_{\max }$ the maximum allowable vertical displacement, $u_{\text {tower }, p}^{k}$ the displacement in $\mathrm{x}$-direction at the top of the tower $p, u_{\max }$ the maximum displacement in x-direction at the top of the tower, $\sigma_{t o p, j}^{k}$ the normal stress in the upper fiber of the deck, $\sigma_{\text {bottom }, j}^{k}$ the normal stress in the bottom fiber of the deck, $\sigma_{C}$ the maximum allowable compression stress in the deck, $\sigma_{T}$ the maximum allowable tensile stress in the deck, $N_{D}$ the nodes of the deck, $E_{D}$ the elements of the deck and $L C$ number of load cases, apart from the load case of self-weight, named as $k=0$.

Table 1: Limit values for the design constraints.

\begin{tabular}{ccccccc}
\hline$\sigma_{M}(\mathrm{MPa})$ & $w_{\max }^{\text {self }- \text { weight }}(\mathrm{m})$ & $w_{\max }^{k}(\mathrm{~m})$ & $u_{\max }^{\text {self-weight }}(\mathrm{m})$ & $u_{\max }^{k}(\mathrm{~m})$ & $\sigma_{C}(\mathrm{MPa})$ & $\sigma_{T}(\mathrm{MPa})$ \\
\hline $0.45 f_{p k}$ & 0.05 & $L_{C} / 500$ & 0.05 & $H_{T} / 500$ & -200 & 300 \\
\hline
\end{tabular}

being $f_{p k}=1860 \mathrm{MPa}, L_{C}=400.14 \mathrm{~m}$ and $H_{T}=127.6 \mathrm{~m}$.

Since the real bridge has a cable configuration of 10 cables in the side span and 10 cables in half of central span, the maximum number of cables proposed for the optimization process was increased to 15 in both cases, namely $N_{C S S}=15, N_{C C S}=15$. This number of cables was chosen in order to cover all the cable configurations. The lower bound and upper bound of the continuous variables are indicated in Table 2.

Table 2: $\quad$ Lower bound and upper bound of design variables for GA.

\begin{tabular}{ccccc}
\hline & $x_{N_{c}+1}, \ldots, x_{N_{C}+N_{C s s}}(\mathrm{~m})$ & $x_{N_{C}+N_{C s}+1}, \ldots, x_{2 N_{C}}(\mathrm{~m})$ & $x_{2 N_{C}+1}, \ldots, x_{3 N_{C}}\left(\mathrm{~m}^{2}\right)$ & $x_{3 N_{C}+1}, \ldots, x_{4 N_{C}}(\mathrm{MPa})$ \\
\hline$l b$ & 0 & 147.42 & 0.001 & 0 \\
$u b$ & 147.42 & 347.49 & 0.0353 & 1860 \\
\hline
\end{tabular}

After submitting the optimization problem, the algorithm was not capable of obtaining a solution that satisfies the design constraints imposed. The proposed optimization problem has 120 design variables, being 30 discrete variables. Consequently, the number of combinations that the genetic algorithm has to contemplate is extremely high, making it inefficient. In order to reduce the magnitude of the problem, the maximum number of cables $\left(N_{C}\right)$ was reduced until $24\left(N_{C S S}=12, N_{C C S}=12\right)$. Moreover, it has been established an interval of cable existence from 18 cables $(9+9)$ to $24(12+12)$. Therefore, only 6 binary variables exist.

It has been considered a population size of 960 individuals for each generation, resulting in a total of 195840 evaluations of the objective function. The genetic algorithm settings are Elite of 4 and Crossover of 0.3 . The algorithm achieves a solution that satisfies the constraints with a configuration of 20 cables $\left(N_{C S S}=11\right.$, $N_{C C S}=9$ ) and a final volume of $76.893 \mathrm{~m}^{3}$. Figure 5 shows the final distribution of design variables. 

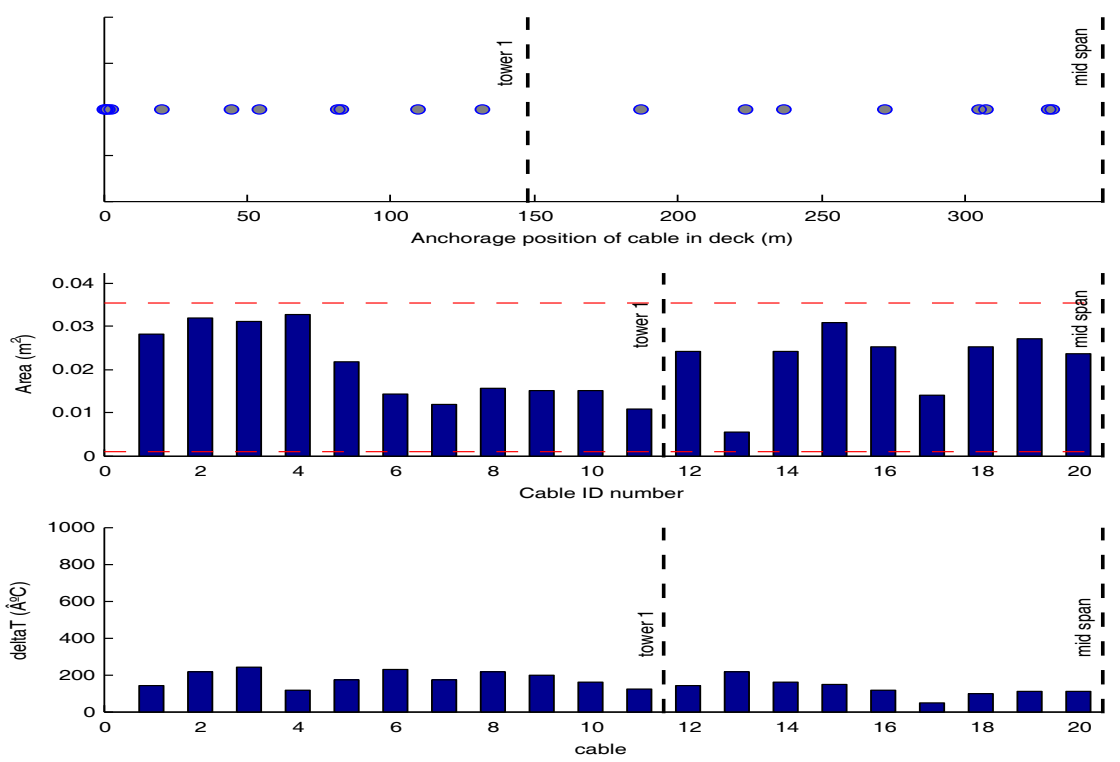

Figure 5: Final design for GA.

\subsubsection{Strategy 2: Gradient method}

The optimization problem can be formulated as defined in equations (5)-(12), substituting the objective function (5) by (13). In this approach a total number of 40 cables was considered $\left(N_{C S S}=20, N_{C C S}=20\right)$.

$$
\min F=\sum_{i=1}^{N_{c}} x_{N_{C}+i} \cdot L_{i}
$$

The initial values, lower bound and upper bound for the design variables are summarized in Table 3.

Table 3: Lower and upper bound and initial values for the design variables.

\begin{tabular}{ccccc}
\hline & $x_{1}, \ldots, x_{N_{C S S}}(\mathrm{~m})$ & $x_{N_{C S S}+1}, \ldots, x_{N_{C}}(\mathrm{~m})$ & $x_{N_{C}+1}, \ldots, x_{2 N_{C}}\left(\mathrm{~m}^{2}\right)$ & $x_{2 N_{c}+1}, \ldots, x_{3 N_{C}}(\mathrm{MPa})$ \\
\hline$l b$ & 0 & 147.42 & $10^{-6}$ & 0 \\
$x_{0}$ & Uniformly distributed & Uniformly distributed & 0.005 & 372 \\
& along the side span & along the central span & 0.0353 & 1860 \\
\hline$b$ & 147.42 & 347.49 & 0.0353 & \\
\hline
\end{tabular}

Stage 1 The result obtained from optimizing the position, area and prestressing forces of the cables is shown in Figure 6 and Table 4. The optimization converges to a non-symmetrical configuration $\left(N_{C S S}=7, N_{C C S}=9\right)$ resulting in a reduction of 24 cables. In the first chart of Figure 6 , the circle marks indicate that a cable exists in that anchorage position on the deck. The cross marks symbolize that the cable does not exist because of the optimum result was the lower limit value $\left(10^{-6} \mathrm{~m}^{2}\right)$. For the area bar chart, the diamond marks show the initial value of the design variables, and the vertical bars indicates their optimum value. 

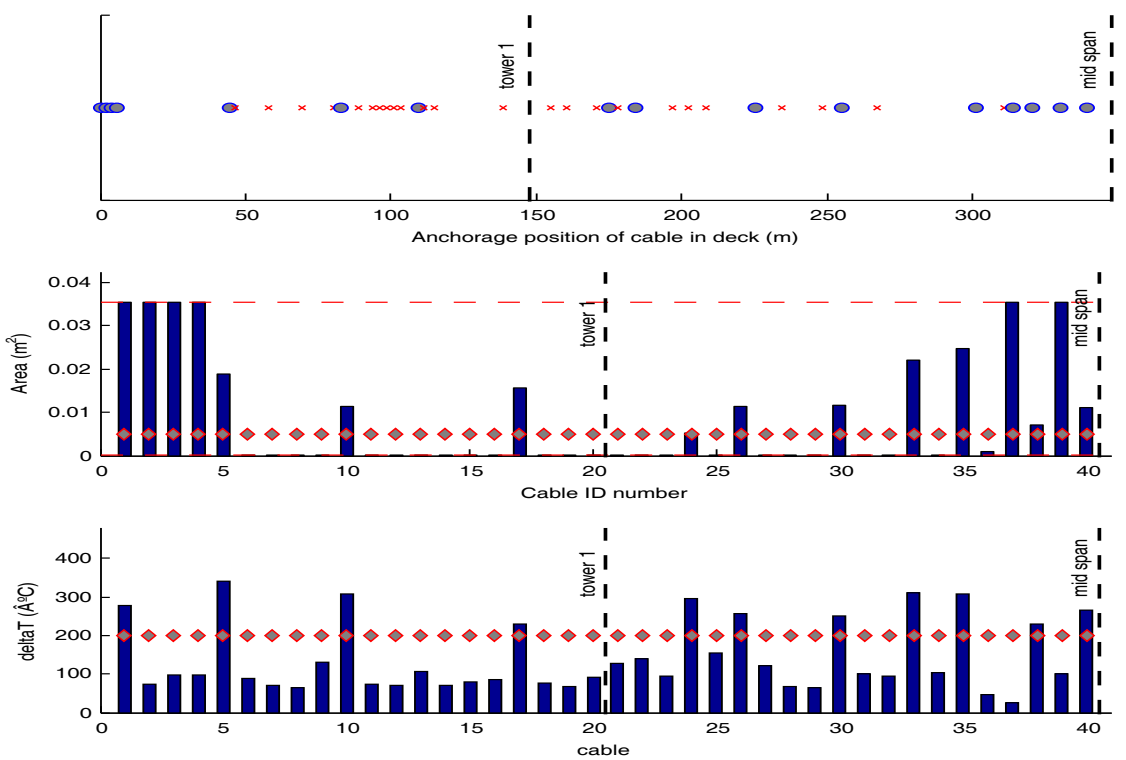

Figure 6: Optimum design of cable anchorage position on the deck and crosssectional areas of the cables for the stage 1 .

Table 4 shows the values of cable position on the deck and areas only for the existent cables.

The final cable system volume was $65.1842 \mathrm{~m}^{3}$ in 20 iterations of the optimizer and 2432 function evaluations.
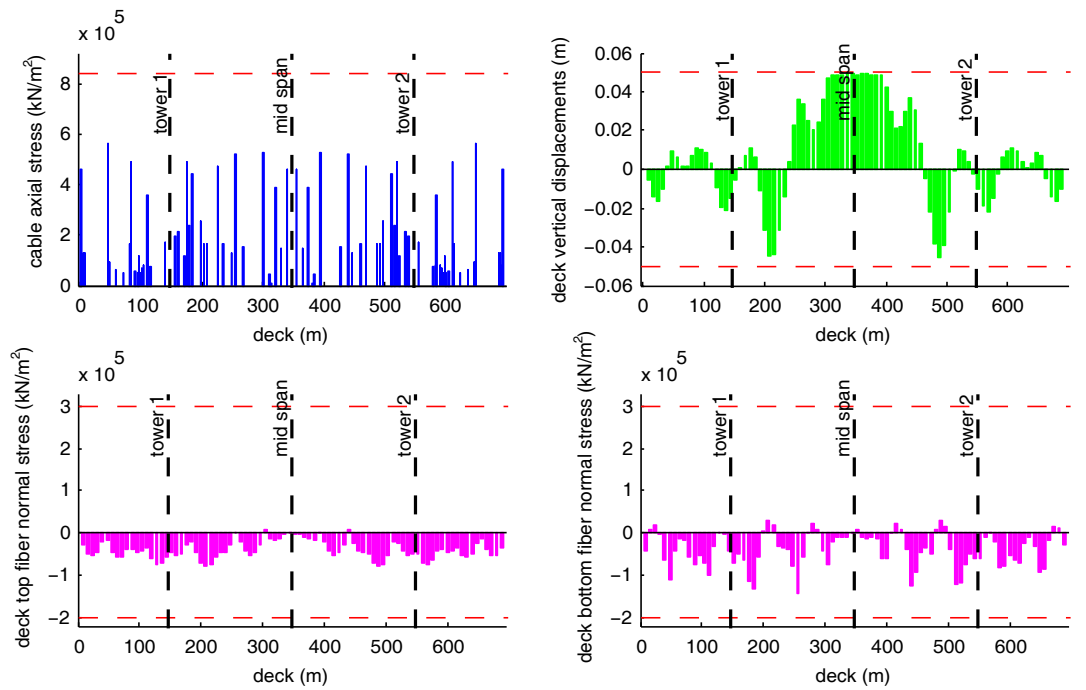

Figure 7: Structural responses for the case of self-weight. 
In Figures 7 and 8, the responses for the most significate load cases are represented. Load Case 5 is the one that have the most number of active constraints, including the horizontal displacement in x-direction at the top of the towers, which is not represented graphically. As it can be seen, all of them satisfy the limits established.

Table 4: Optimum design of cable anchorage distribution on the deck and cross-sectional areas of the cables for the stage 1 .

\begin{tabular}{|c|c|c|c|c|c|c|c|c|c|c|c|}
\hline Cable & \multicolumn{2}{|l|}{1} & \multicolumn{2}{|r|}{2} & 3 & 4 & \multicolumn{2}{|l|}{5} & \multicolumn{2}{|r|}{10} & 17 \\
\hline Position (m) & \multicolumn{2}{|c|}{0.000} & \multicolumn{2}{|c|}{2.000} & 3.990 & 5.990 & \multicolumn{2}{|c|}{44.467} & \multicolumn{2}{|c|}{82.813} & 109.283 \\
\hline Area $\left(\mathrm{m}^{2}\right)$ & \multicolumn{2}{|c|}{0.035343} & \multicolumn{2}{|c|}{0.035343} & 0.035343 & 0.035343 & \multicolumn{2}{|c|}{0.018887} & \multicolumn{2}{|c|}{0.011242} & 0.015612 \\
\hline $\begin{array}{l}\text { Prestressing } \\
\text { force }(\mathrm{MPa})\end{array}$ & \multicolumn{2}{|c|}{517.59} & & 38.23 & 183.44 & 182.62 & \multicolumn{2}{|c|}{635.36} & \multicolumn{2}{|c|}{569.58} & 428.03 \\
\hline Cable & 24 & & 6 & 30 & 33 & 35 & 37 & & 38 & 39 & 40 \\
\hline Position (m) & 174.671 & 183 & .823 & 225.536 & 254.937 & 300.819 & 313.540 & 320 & .609 & 330.447 & 339.490 \\
\hline Area $\left(\mathrm{m}^{2}\right)$ & 0.005181 & 0.01 & 1456 & 0.011592 & 20.022043 & 0.024645 & 0.035343 & 0.00 & 7091 & 0.035343 & 30.011014 \\
\hline $\begin{array}{l}\text { Prestressing } \\
\text { force }(\mathrm{MPa})\end{array}$ & 548.06 & & 6.59 & 467.04 & 575.70 & 571.02 & 48.17 & & 4.98 & 184.63 & 496.28 \\
\hline
\end{tabular}
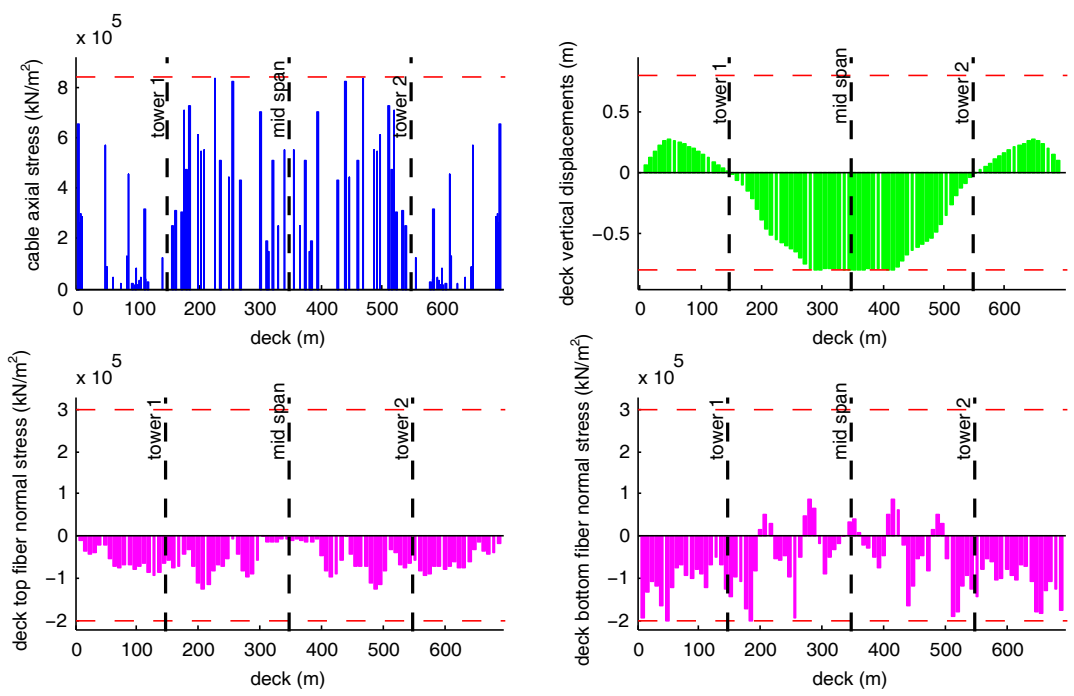

Figure 8: Structural responses for the load case 5.

Stage 2 After suppressing the cables having lower limit value of area it is necessary to repeat the optimization process (Figure 9 and Table 5), since some constraints violations existed in the vertical displacement in the deck for selfweight (2.94\% violation) and for the load case 5 (1.57\% violation). 

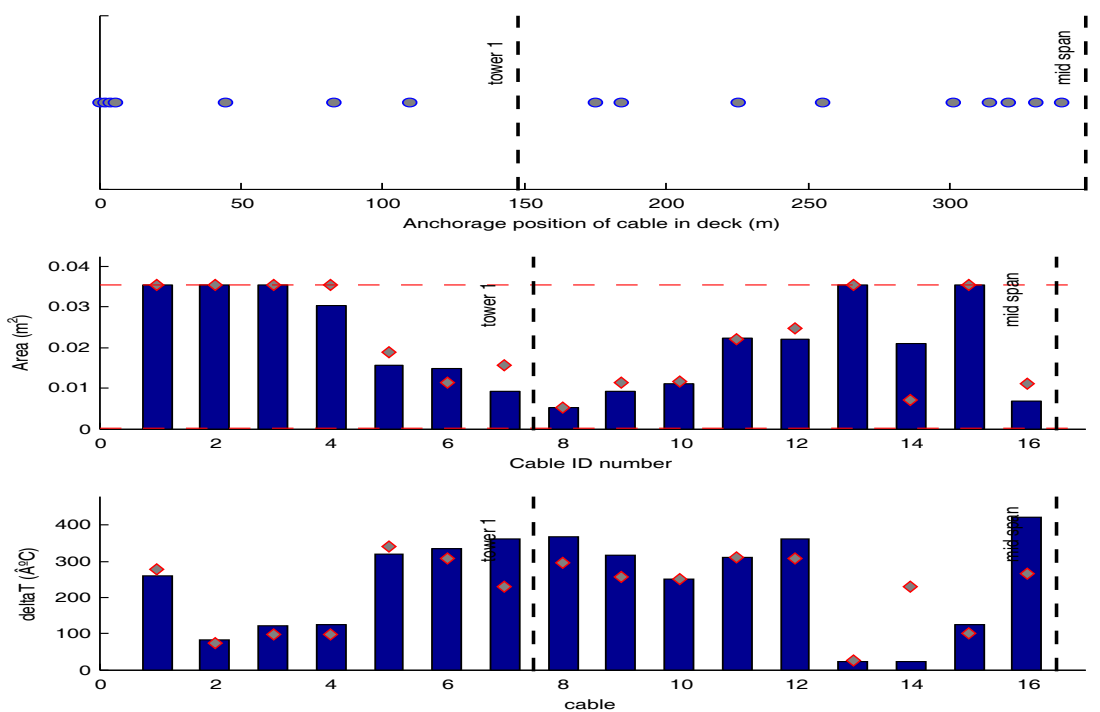

Figure 9: Optimum design of cross-sectional areas and prestressing forces.

Table 5: Optimum design of cross-sectional areas and prestressing forces of the cables for stage 2 .

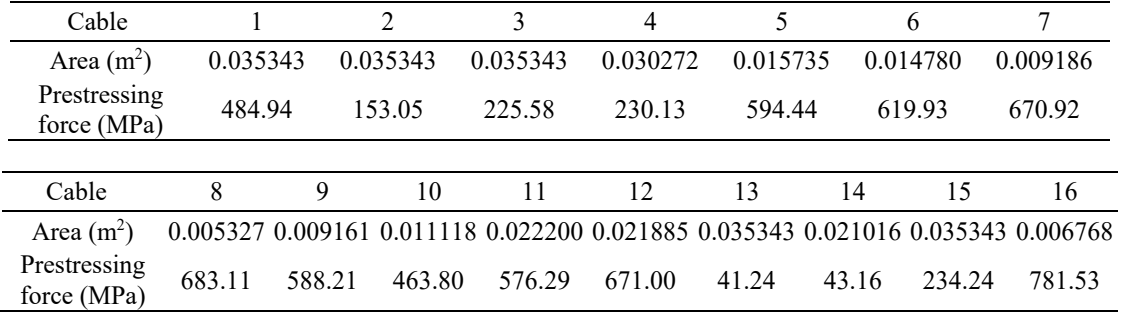

The new total volume of cables has a value of $64.513 \mathrm{~m}^{3}$.

Stage 3 The area values obtained in stage 2 are adjusted to the nearest integer number of commercial strands composed of 7 wires of $0.5 \mathrm{~cm}$ of diameter, (area of $98.71 \mathrm{~mm}^{2}$ ), resulting in a $0.07 \%$ volume increase. After this updating, it was tested the fulfilment of the design constraints. The final cable areas are presented in Table 6. 
Table 6: Optimum design corresponding an integer number of strands.

\begin{tabular}{|c|c|c|c|c|c|c|c|c|}
\hline Cable & 1 & 2 & 3 & 4 & 5 & & 6 & 7 \\
\hline Area $\left(\mathrm{m}^{2}\right)$ & 0.035437 & 0.035437 & 0.035437 & 0.030304 & 0.0157 & 994 & .014807 & 0.009279 \\
\hline No. of strands & 359 & 359 & 359 & 307 & 160 & & 150 & 94 \\
\hline Cable & 8 & 10 & 11 & 12 & 13 & 14 & 15 & 16 \\
\hline Area $\left(\mathrm{m}^{2}\right) \quad 0$ & 0.0053300 .00 & 91800.01115 & 40.022210 & 0.021914 & 0.035437 & 0.021025 & 250.035437 & 370.006811 \\
\hline No. of strands & 54 & $3 \quad 113$ & 225 & 222 & 359 & 213 & 359 & 69 \\
\hline
\end{tabular}

\section{Conclusions}

Several conclusions can be drawn from this work:

1. Genetic algorithm is inefficient when considering a large number of design variables of different nature, since the number of combinations that the algorithm has to contemplate is extremely high.

2. With lower number of discrete variables, Genetic Algorithm is able to converge to a solution that satisfies the design constraints established but it is not effective in finding the global minimum solution.

3. Given the mechanical properties and dimensions of the deck and towers of a bridge, the gradient-based algorithm provides the best number of cables, their anchorage position, optimum areas and prestressing forces guaranteeing the minimum volume of cables, verifying the established design constraints.

4. The results in both approaches converges to a different number of stays each side of the towers.

\section{Acknowledgement}

The research leading to these results has received funding from the Spanish Minister of Economy and Competitiveness (MINECO) with reference BIA201341965-P.

\section{References}

[1] Chen D.W., Au F.T.K., Tham L.G., Lee P.K.K. Determination of initial cable forces in prestressed concrete cable-stayed bridges for given design deck profiles using the force equilibrium method. J Comput Struct; 74, pp. 1-9, 2000.

[2] Janjic D., Pircher M., Pircher H., Optimization of cable tensioning in cablestayed bridges. J Bridge Eng, 8, pp. 131-137, 2003.

[3] Hassan M.M., Nassef A.O., El Damatty A.A., Determination of optimum posttensioning cable forces of cable-stayed bridges. Eng Struct; 44 pp. 248$259,2012$. 
40 High Performance and Optimum Design of Structures and Materials II

[4] Baldomir A., Hernandez S., Nieto F., Jurado J.A. Cable optimization of a long span cable stayed bridge in La Coruna (Spain). Advances in Engineering Software, 41(7-8), pp. 931-938, 2010.

[5] Simoes L.M.C., Negrao J.H.J.O., Sizing and geometry optimization of cable-stayed bridges. Computers and Structures, 52, pp. 309-321, 1994.

[6] Negrao J.H.J.O., Simoes L.M.C., Optimization of cable-stayed bridges with three-dimensional modelling. Computers and Structures, 64, pp. 741-758, 1997.

[7] Simões L.M.C., Negrão J.H.J.O., Optimization of cable-stayed bridges with box-girder decks. Advances in Engineering Software, 31, pp. 417-423, 2000 .

[8] Martins A.M.B., Simões L.M.C., Negrão J.H.J.O., Optimization of cable forces on concrete cable-stayed bridges including geometrical nonlinearities. Computers and Structures, 155, pp. 18-27, 2015.

[9] Baldomir A., Tembrás E., Hernández S. Optimization of cable weight in multi-span cable-stayed bridges. Application to the Forth Replacement Crossing. Proceedings of Multi-Span Large Bridges, 2015.

[10] MATLAB 2013a documentation, Mathworks, Natick, Massachusetts, USA, 2013.

[11] ABAQUS 6.13 Documentation, Dassault Systèmes Simulia Corp., Providence, Rhode Island, USA, 2013. 